Asian Pacific Journal of Reproduction

Journal homepage: www.apjr.net

\title{
Male masturbation device for the treatment of delayed ejaculation: A case report
}

\author{
Rodríguez JE ${ }^{\bowtie}$, Picazo JA, López E \\ Research Department of Instituto Sexológico Murciano, C/Periodista Encarna Sánchez, 22, 030007 Murcia, Spain
}

\section{ARTICLE INFO}

Article history:

Received 1 May 2017

Revision 20 May 2017

Accepted 10 June 2017

Available online 1 July 2017

Keywords:

Delayed Ejaculation

Male

Device

Treatment

Ejaculation disorders

\section{ABSTRACT}

Delayed ejaculation is a rare condition with different etiologies. Majority of cases of delayed ejaculation have a strong psychological/behavior component. A 48-year-old male with a diagnostic of delayed ejaculation acquired was encouraged to make an exercise protocol using a masturbation device for $8 \mathrm{wk}$, the percentage of intercourse successful a month after finish protocol exercise was $81 \%$.

\section{Introduction}

Delayed ejaculation (DE) is the least understood and least common male sexual dysfunction. Any procedure or disease, as well as some drugs, that disrupts the nervous systems path to the genitals may produce delay on ejaculation[1].

In the last 5 years in our clinic, there has been an increase among men who cannot ejaculate inside vagina for psychological factors, even though they are able to ejaculate through masturbation. Masturbation style that it is not easily duplicated by their partner's hand, mouth, or vagina, disparity between the reality of sex with the partner, the sexual fantasy used during masturbation for a prolonged period of time and performance anxiety are the most common causes of DE[2].

We are going to describe our case, a 48-year-old man, who has an unstable relationship and referred to us from urological unit suffer from delayed ejaculation acquired.

\section{Case history and assessment}

The 48-year-old male was originally from Murcia and worked like a phone technician in a multinational for last 30 years. He divorced

Corresponding author: Rodríguez J.E., Instituto Sexológico Murciano, C/ Periodista Encarna Sánchez, 22, 030007 Murcia, Spain.

Tel: +34 868941418

E-mail: jesuseugenio@isemu.es, joseantonio.picazo@isemu.es, elena.lopez@isemu.es and lived alone. Since he divorced 6 years ago, he has not had an intercourse until 2 mo before first visit an urologist for has no orgasms at all after prolonged intercourse (more than $30 \mathrm{~min}$ ). $\mathrm{He}$ used to masturbate six times per week. The method of masturbation of this patient was to use a computer to watch pornography on the Internet, grasping the penis softly but firmly in his dominant hand, rising and falling repeatedly and increasing speed.

The patient had ever felt distress or guilt for the sexual activities and the masturbation, and he thought unsatisfactory with current sexual life. This patient had no co-morbid mental diagnoses and urologist reject organic etiology, the average masturbation ejaculatory latency time measure by stopwatch record during $2 \mathrm{wk}$ was around $4 \mathrm{~min}$. Two month before visit our service he started a relationship with a 45-year-old woman, he attempted 9 sexual intercourse and none were successful.

There are different treatment options reported for DE[3,4]. Sex therapy for DE acquired in our clinic may include some of the

This is an open access article distributed under the terms of the Creative Commons Attribution-Non Commercial-Share Alike 3.0 License, which allows others to remix, tweak and buid upon the work non-commercially, as long as the author is credited and the new creations are licensed under the identical terms.

For reprints contact: reprints@medknow.com

C2017 Asian Pacific Journal of Reproduction Produced by Wolters Kluwer- Medknow

How to cite this article: Rodríguez JE, Picazo JA, López E. Male masturbation device for the treatment of delayed ejaculation: A case report. Asian Pac J Reprod 2017; 6(4): 191-192. 
following: Cognitive Behavioural Therapy (CBT), anxiety reduction/ desensitization with partner, education and masturbatory retraining.

In this case, we put the focus in a new masturbatory retraining use a masturbation aid device with a homework protocol of exercise for $8 \mathrm{wk}$. The patient was encouraged to alter the style of masturbation (only use of Tenga device and lubricant) and to approximate (in terms of speed, pressure, and technique) the stimulation likely to be experienced through vaginal stimulation.

Patient used a device called FLIP HOLE® and lubricant called REAL $®$, which was a Japanese device of masturbation aid produced by the company TENGA, Co., personal lubricants, and other sexual products were sold under this brand[5]. After performing a demonstration of how it is used, it was given the following rules of use. "During the next $8 \mathrm{wk}$ you will use this device without partner for 3 times per week, everytime you should be at least masturbating until ejaculate."

During $8 \mathrm{wk}$, the patient had to use the device until he ejaculated. First 2 wk, he need to move up and down repeatedly and increase the speed using his stronger hand. After its 4 wk using his non dominant hand, and last $2 \mathrm{wk}$ of protocol exercise had to masturbate keeping his hand still and use his body to move (Figure 1).

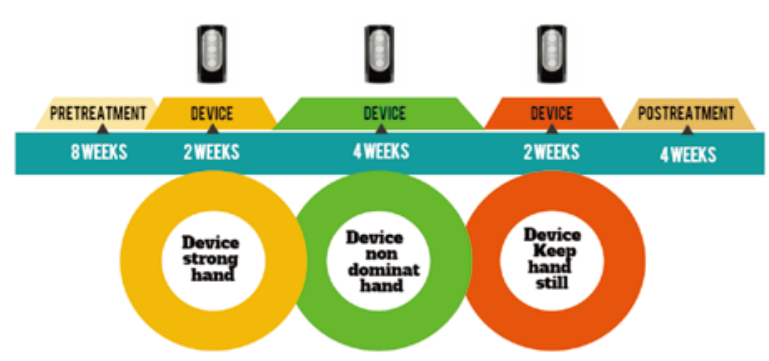

Figure 1. Case study timeline.

First intercourse successful was in week 5 , the last 2 wk of exercise he was able to ejaculate inside his partner 3 times, the percentage of intercourse successful one month after finish protocol exercise was $81 \%$ (Figure 2). As a main outcome, measure used the percentage of sexual intercourse attempts that were successful, determined from an ejaculation during sexual intercourse in less than $25 \mathrm{~min}$.

$\%$ Ejaculation during intercourse successful
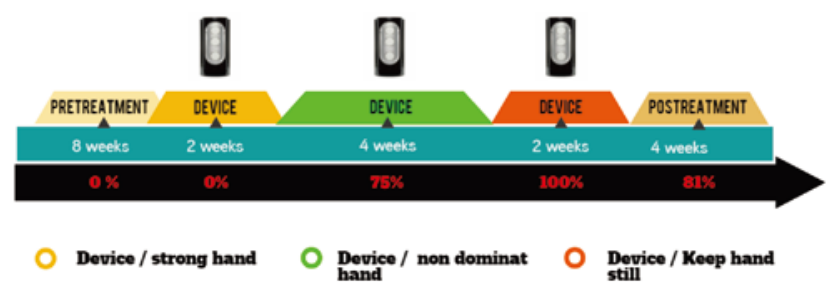

Figure 2. Rate of ejaculation during intercourse successful.

\section{Discussion}

Delayed ejaculation is a small but important subtype of ejaculatory dysfunction, with prevalence, despite the difficulty in defining it, estimated at $1 \%-4 \%[1,6]$. Treatment is etiologically based and may combined medical and sociological approaches. When no organic cause of DE has been identified and psychogenic etiology are suspected, then consultation with a sexual therapist is warranted; but the accessibility to this treatment is very limited, also, the cost, the lack of well-defined cognitive behaviour protocol treatment and the need for collaboration on the part of the couple does that many men could not benefit from the same one. New treatment lines are necessary therefore for these men that they complement the poor arsenal therapeutic available $[1,6]$.

The treatment of DE should seek to remove or correct its cause. This treatment is particularly suitable when the cause of DE is an idiosyncratic masturbation style that cannot be replicated with a woman partner using her hand, mouth, or vagina. This factor has been frequently reported in DE during intercourse[1,6].

In relation to the actual treatment, the masturbation retraining with this device has three big advantages, the first one who does not need the collaboration on the part of the couple, the second one who lacks side effects and the third one that it is not necessary to come to the consultation of a specialist for its use.

Future research should be oriented to prove if the outcome of treatmenttested in this case study could be generalized to the rest of patients with DE.

\section{References}

[1]Perelman MA. Delayed ejaculation. J Sex Med 2013; 10(4): 1189-1190.

[2]Althof SE. Psychological interventions for delayed ejaculation/orgasm. Int J Impot Res 2012; 24(4): 131-136.

[3]Sadowski DJ, Butcher MJ, Köhler TS. A review of pathophysiology and management options for delayed ejaculation. Sex Med Rev 2016; 4(2): $167-176$.

[4]Shin DH, Spitz A. The evaluation and treatment of delayed ejaculation. Sex Med Rev 2014; 2(3-4): 121-133.

[5]Kobori Y, Aoki H, Nishio K, Sato R, Ashizawa Y, Yagi H, et al. Rehabilitation for severe delayed ejaculation (intravaginal ejaculation disorder) with use of a masturbation aid. Asian Pac J Reprod 2012; 1(4): 262-264.

[6]Sadowski DJ, Butcher MJ, Köhler TS. Delayed ejaculation: Medical and psychological treatments and algorithm. Curr Sex Heal Reports 2015; 7(3): 170-179. 